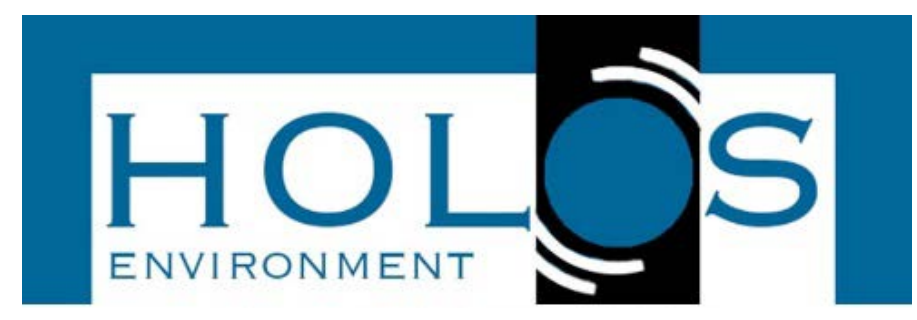

\title{
OS PRINCÍPIOS DA SUSTENTABILIDADE COMO NORTEADORES NA GESTÃO DOS RESÍDUOS SÓLIDOS URBANOS
}

\author{
THE PRINCIPLES OF SUSTAINABILITY AS GUIDING THE MANAGEMENT OF \\ MUNICIPAL SOLID WASTE
}

\author{
Amanda Rodrigues Santos Costa $^{1}$; Sara Maria Gomes Pinheiro ${ }^{1}$; \\ Alcione Moraes de Melo $^{1}$; Soraya Giovanetti El-Deir ${ }^{1}$
}

Artigo recebido em: 16/06/2016 e aceito para publicação em: 16/10/2017.

DOI: http://dx.doi.org/10.14295/holos.v17i1.11510

\begin{abstract}
Resumo: A preocupação ambiental é um tema crescente em toda a sociedade, pois o meio ambiente e a preservação deste afetam diretamente a qualidade de vida e a saúde humana. Nesse sentido, a grande produção de resíduos sólidos em centros urbanos contribui para a crise ambiental devido a um modelo econômico que incentiva padrões de consumo inadequados e desperdícios por parte da população. Portanto, diante desta problemática, o presente estudo pretende abordar a discussão sobre os princípios da sustentabilidade na gestão dos resíduos sólidos, além de analisar a Política Nacional de Resíduos Sólidos à luz do pensamento sistêmico. A visão sistêmica trata da ideia de interdependência entre elementos de um sistema, de forma que não é possível analisar um todo a partir do isolamento das partes. Desta forma, a gestão e o gerenciamento dos resíduos devem ocorrer de forma integrada, como prediz a legislação, considerando as dimensões econômica, social, ambiental e cultural, envolvendo os diversos setores - governo, setor privado e sociedade - e os sistemas interligados aos resíduos.
\end{abstract}

Palavras-chave: Princípios da sustentabilidade. Resíduos sólidos. Visão sistêmica.

Abstract: Environmental concern is a growing theme in the whole society, for the environment and its preservation directly affects the quality of life and human health. Contributing to the environmental problem is the production of solid waste in urban centers, which has increased due to an economic model that encourages consumption patterns and inadequate waste from the population. Therefore, it is urgent to adopt management models that include the concept of sustainability. This study intends to deepen the discussion on the principles of sustainability in relation to the issue of solid waste, in addition to analyzing the National Policy on Solid Waste in the light of systems thinking. A systemic view is the idea of interdependence between elements of a system so that cannot parse a whole from the isolation of the parties. Thus, the management and the management of waste should take place in an integrated manner, as predicts the legislation, considering the economic, social, environmental and cultural dimensions and involving the various sectors - government, private sector and society - and the various interconnected systems to residues.

Keywords: Principles of sustainability. Solid waste. Systemic view.

\footnotetext{
${ }^{1}$ Universidade Federal Rural de Pernambuco (UFRPE), Recife, PE. Emails: (amandarsc@gmail.com; sara gpinheiro@hotmail.com; alcione mm@hotmail.com; sorayageldeir@gmail.com)
} 


\section{INTRODUÇÃO}

A preocupação ambiental é um tema crescente em toda a sociedade, pois o meio ambiente e a preservação deste afetam diretamente a qualidade de vida e a saúde humana. Inserida nesta questão está a gestão e o gerenciamento adequados dos resíduos produzidos pelas atividades antrópicas, porque esses, quando não manejados adequadamente, apresentam potencial impactante para o funcionamento dos ecossistemas, portanto, devem ser tratados com vistas à sustentabilidade.

O termo sustentabilidade é utilizado em vários campos de aplicação como na Ecologia, na Administração e nas Engenharias e está presente nas discussões das políticas públicas nacionais e internacionais. O conceito de sustentabilidade versa sobre como os seres humanos devem se relacionar com a natureza, uns com os outros e às futuras gerações, sendo coerente com o crescimento econômico sustentado e com a justiça social, no uso parcimonioso dos recursos naturais (SARTORI et al., 2014).

Desta forma, a sustentabilidade é abordada a partir das dimensões econômica, social, ambiental e político-institucional (RODRIGUES; RIPPEL, 2015), buscando alcançar o equilíbrio entre estas, isto porque o desenvolvimento orientado pela sustentabilidade deve considerar outras dimensões, além da preservação ambiental e da produtividade econômica (LEANDRO et al., 2015). Na atualidade, são necessários estudos aprofundados sobre as questões que envolvem tais abordagens, uma vez que os interesses governamentais, sociais e corporativos globais estão cada vez mais voltados para o ambiente como um recurso estratégico para o desenvolvimento institucional.

As discussões sobre sustentabilidade têm resultado na adoção deste conceito no meio empresarial, nas políticas públicas e nas legislações. Nesse contexto, a produção de resíduos sólidos em centros urbanos é um dos principais contribuintes da crise ambiental na dimensão local, gerado por um modelo econômico que incentiva padrões de consumo inadequados e desperdícios por parte da população (POLAZ; TEIXEIRA, 2009).

Esse modelo é baseado em uma ideia individualista, que desconsidera as consequências de tal postura para o ambiente; enquanto, na verdade, há uma direta relação entre as atividades humanas e a alteração do meio. Segundo Capra (1996), existe uma interdependência fundamental entre todos os fenômenos e a sociedade, estando cada indivíduo inserido em todos os processos cíclicos da natureza, sendo destes dependentes. Este é um dos fundamentos da visão sistêmica ou holística. 
Para alcançar uma relação harmoniosa entre os seres humanos e a natureza, é necessário utilizar os princípios provenientes dos novos paradigmas e as teorias da ciência, já que a inadequada convivência com o meio ambiente é resultado, em grande parte, da visão mecanicista do mundo. Essa visão analisa as partes de um todo isoladamente, contrariamente à visão holística. Sendo assim, as novas abordagens científicas contribuem, juntamente, com os princípios éticos, sociais e econômicos, para a formação de novos modelos de desenvolvimento da sociedade (OLIVEIRA, 2005).

Inserida neste contexto de novas abordagens, a Política Nacional de Resíduos Sólidos (BRASIL, 2010), legislação voltada para gestão e gerenciamento dos resíduos, inclui a ideia da visão sistêmica como um dos princípios norteadores da lei e, portanto, fundamenta conceitos como o da gestão integrada dos resíduos e da responsabilidade compartilhada pelo ciclo de vida dos produtos.

O presente estudo pretende abordar a discussão sobre os princípios da sustentabilidade com relação à problemática dos resíduos sólidos, além de analisar a Política Nacional de Resíduos Sólidos à luz do pensamento sistêmico. Esta pesquisa tem uma abordagem qualitativa e um caráter descritivo, visto que busca compreender uma temática e os conceitos relacionados a ela, não havendo a necessidade de fórmulas ou de análises estatísticas. Para tanto, realizar-se-á levantamento de dados secundários através de pesquisa bibliográfica em artigos científicos como base para discussões e análises críticas (SILVA; MENEZES, 2005).

O estudo foi realizado tomando por referencial teórico os indicadores "sustentabilidade", "princípios da sustentabilidade" e "resíduos sólidos". A discussão desses temas ocorreu a partir do conceito da visão sistêmica, buscando relacionar os indicadores aos preceitos de sustentabilidade, à luz da Política Nacional. Este trabalho pretende ser um avanço nestas discussões, auxiliando no aprofundamento teórico sobre a temática.

De maneira a introduzir o leitor no tema do artigo e facilitar a compreensão dos assuntos discutidos, inicialmente revisa-se o conceito e a evolução do termo sustentabilidade, através dos principais eventos e publicações internacionais; em seguida, apresentam-se os princípios da sustentabilidade pela visão de Rhode (1995) e a problemática do tema principal, os resíduos sólidos urbanos; discute-se a relação entre um dos princípios da sustentabilidade, a visão sistêmica, com a gestão dos resíduos sólidos e a legislação vigente, a Política Nacional dos Resíduos Sólidos; por fim, seguem as considerações finais. 


\section{A EVOLUÇÃO DA SUSTENTABILIDADE}

\subsection{Histórico}

Os conceitos de desenvolvimento sustentável e sustentabilidade, em alguns momentos, confundem-se e são tratados como sinônimos. O Relatório Brundtland propôs o conceito de desenvolvimento sustentável, o qual se refere ao desenvolvimento que satisfaça as necessidades do presente, sem comprometer as futuras gerações de satisfazerem suas próprias necessidades (ONU, 1987). Neste momento, o elemento humano foi considerado, ou seja, não se trata somente do impacto da atividade econômica sobre o meio ambiente, mas também as consequências dessa relação sobre a qualidade de vida e bem-estar da população presente e futura. Assim, os conceitos de desenvolvimento sustentável e sustentabilidade são basilares e complementares, sendo o primeiro o caminho para se alcançar o segundo (FERNANDES; CANDIDO, 2015).

Os fundamentos e as bases para o conceito de sustentabilidade começaram a se delinear ainda na década de 20, quando foi lançado o "First Essay on Population", de Malthus, que alertou para o desequilíbrio entre o crescimento populacional e os recursos alimentares, cuja solução dependia de comportamentos individuais (OLIVEIRA et al, 2010). Para Malthus, a população mundial, quando não controlada, crescia em progressão geométrica, e a oferta de alimentos em progressão aritmética (BATISTA, 2013). Apesar de a sua teoria mostrar-se errada, pois não considerou o fator tecnológico para o aumento da produção de alimentos, Malthus alertou para o fato de questões ambientais limitarem a população.

As guerras e as questões econômicas fizeram com que o tema ficasse em segundo plano até a década de 60, com a publicação do livro "Silent Spring", que alertou a respeito do problema da saúde pública e do meio ambiente quanto ao uso excessivo de inseticidas na agricultura (BRITO, 2010). Ainda na década de 60, pode-se destacar o trabalho de Bouding, publicado como "Spaceship Earth", que comparou a Terra a uma nave espacial, analisando o planeta como um sistema fechado, com recursos limitados.

Discussões referentes às limitações dos recursos naturais fez com que os estudiosos da época fundassem o Clube de Roma, em 1968 (OLIVEIRA et al., 2010). A maior contribuição dessa equipe foi o documento intitulado "The limits to growth", liderado por Dana Meadows e publicado em 1972. Esta publicação alertava para a necessidade de um equilíbrio global entre o crescimento da população, o desenvolvimento econômico e a 
atenção aos problemas ambientais, através de simulações catastróficas de como seria o planeta dentro de 100 anos, caso persistisse o modelo de desenvolvimento da época (ARAÚJO et al., 2006).

Decorrente da intensificação da preocupação ambiental, em 1972, a Organização das Nações Unidas (ONU) lançou a primeira Conferência Mundial sobre o Homem e o Meio Ambiente, conhecida como Conferência de Estocolmo, a qual reconheceu os impactos das atividades antrópicas no meio ambiente e os riscos potenciais, bem como a necessidade de ações corretivas (GURSKI, 2012). Só em 1987, através do Relatório Brundtland, também conhecido como "Our Commom Future", foi consolidado o conceito de desenvolvimento sustentável e a necessidade de mudanças de base (OLIVEIRA et al., 2010).

O grande marco global no debate sobre sustentabilidade foi a Conferência da ONU sobre Meio Ambiente e Desenvolvimento, pois reuniu representantes políticos de 178 países. Ocorrida em 1992 no Rio de Janeiro, ficou conhecida como ECO-92. Os documentos originados desta conferência foram a Convenção sobre biodiversidade e alterações climáticas, a Convenção das florestas, a Carta da Terra e a Agenda 21 Global. Essa última consitiu-em um plano de ação, de alcance mundial, para regulamentar o desenvolvimento baseado na sustentabilidade, o que requer mudanças de hábitos, tal como a produção e consumo em relação à gestão dos resíduos (LIRA; FRAXE, 2014). Tal Agenda pautou a necessidade de produzir informações relacionadas ao estado do desenvolvimento (RODRIGUES; RIPPEL, 2015). Estes devem ser norteados pelos princípios da sustentabilidade.

\subsection{Princípios da Sustentabilidade}

A comunidade científica global vem discutindo os conceitos e os fundamentos da sustentabilidade e alerta para o fato de que a busca pelo desenvolvimento econômico por si só é insustentável. Se observado apenas o aspecto econômico, este incentiva a acumulação cada vez mais rápida de riqueza. Já a alteração dos ciclos biogeoquímicos e dos ecossistemas fundamentais para sustentação da vida não são considerados pelo olhar economicista. Por outro lado, existe a crença constante de que a tecnologia resolverá os efeitos negativos provocados por este modelo pós-moderno (RHODE, 1998).

Mesmo com alguns problemas ambientais já em curso, predominantemente, a natureza ainda é vista como fonte de recursos e riqueza ou local para disposição dos 
resíduos das atividades humanas. A maneira como os indivíduos atuam sobre o meio ambiente é resultado de um sistema de ideias, crenças e valores dominantes, pressuposições explícitas ou implícitas sobre sua essência (BURRELL; MORGAN, 1979). Essas pressuposições constituem os paradigmas, que vão constituir os princípios de organização do pensamento, os quais vão exercer influência sobre a visão de mundo dos indivíduos e comportamento assumido por eles (SILVA, 2014). Constitui uma herança cultural que permanece intacta, sem que o homem adapte aos novos tempos de carência de recursos (BATISTA, 2013).

Desta forma, a busca do desenvolvimento sustentável dependerá de mudanças dos paradigmas e da adoção de diferentes hábitos, que recusem uma visão mecanicista e antropocêntrica. Para Ferreira e Bomfim (2010), o próprio conceito de desenvolvimento sustentável denota uma ótica antropocêntrica, pois busca a preservação do planeta para as futuras gerações, demonstrando uma visão utilitária das formas de concepção da vida planetária, focando mais no aspecto político do que na elaboração de ações de cunho social, participativo e global.

Grün (1996) acredita que a visão antropocêntrica esta presente desde o antigo testamento, quando no livro dos Gênesis há a passagem em que Deus diz aos homens que ele domine os peixes do mar, as aves do céu, os animais domésticos, todas as feras e todos os répteis que rastejam sobre a terra; e tomou maiores proporções a partir do pensamento filosófico mecanicista de René Descartes. Para o citado autor, uma das principais causas da degradação ambiental está no fato da humanidade viver sobre sob a égide de uma ética antropocêntrica, em um sistema de valores no qual o Homem é o centro de tudo.

Mas como trata Capra (1996, p. 22), “... há soluções para os principais problemas de nosso tempo, algumas delas até mesmo simples. Mas requerem uma mudança radical em nossas percepções, no nosso pensamento e nos nossos valores". A partir dos novos pensamentos e das teorias do conhecimento originadas das mudanças de paradigma, é possível identificar os princípios filosófico-científicos norteadores da sustentabilidade, os quais são, segundo Rhode (1998), a contingência ou a autopoiese, a complexidade, a sistêmica, a recursividade, a conjunção e a interdisciplinaridade.

Esses princípios recusam o pensamento mecânico-reducionista, contrapondo-o com o holístico. Há integração entre as partes, os campos dos saberes e a teoria da autoorganização. Essa se refere às propriedades de um sistema, especialmente aos que são vivos, levando em consideração as conexões aparentes e ocultas entre os diversos 
elementos, não sendo o simples somatório das partes que o compõem (RHODE, 1998). Os princípios da sustentabilidade devem ser os norteadores para soluções dos problemas ambientais, incluindo questões relativas ao gerenciamento e à gestão dos resíduos sólidos.

\section{PROBLEMÁTICA DOS RESÍDUOS SÓLIDOS NO BRASIL}

A cultura das comunidades, aliada ao desenvolvimento tecnológico, ao nível econômico, aos aspectos sociais como geração e gênero, assim como aos valores individuais de cada pessoa, apresentam correlação com os padrões de consumo. Esse padrão resulta em uma maior produção de resíduos e nos problemas relacionados à disposição final (MUCELIN; BELLINI, 2008).

Segundo Echegaray e Afonso (2014), existe um dilema na sociedade moderna em relação à solução das questões ambientais que versa sobre a escolha entre mudanças comportamentais ou a confiança em saídas tecnológicas. Essa última, apesar de reconhecida como parte importante do processo, não é suficiente para tratar o problema como um todo, havendo a necessidade de incluir as dimensões cultural e social. Tal fato contribui para a emergência de um consumo consciente de produtos, dentro de um contexto de mudanças de valores e de estilo de vida.

O crescimento populacional e a aceleração da urbanização ao longo do tempo mudou a dinâmica da relação entre o homem e a natureza. Odum (1988) considera que estes fatores, especialmente a partir do século $X X$, promoveram mudanças no planeta mais do que qualquer outra atividade antrópica. Nesse contexto, as cidades estão no foco da problemática ambiental, pois a concentração dos seres humanos e o processo de dominação do espaço urbano aceleram a degradação do meio (PEREIRA, 2012). No entanto, uma análise histórica acerca do surgimento das cidades e da gestão de resíduos sólidos evidencia que esta não é uma discussão exclusiva da contemporaneidade.

As primeiras comunidades humanas surgiram com a popularização da prática da agricultura, ocorrida no período pré-histórico conhecido como Neolítico. Neste, homens nômades que se alimentavam da caça, pesca e coleta de vegetais, passaram a conviver em comunidades agrícolas. A produção não absorvida pela economia de subsistência passou a dar base à estruturação do escambo. Desta forma, as cidades surgem devido ao início do comércio e da manufatura especializada, com o acréscimo da produção 
agrícola de alimentos. Estas passam a ser uma localidade de afirmação de novas relações de poder (RÊGO, 2012).

As cidades continuaram transformando-se. Porém, com a Revolução Industrial no século XVIII, este processo foi acelerado através da industrialização. Iniciou-se a urbanização, provocando um êxodo do homem do campo para as cidades. Nesta época, o avanço da medicina favoreceu o crescimento populacional e o consequente aumento da expectativa de vida (RÊGO, 2012). A partir de então, os impactos ambientais passaram a ter um grau de magnitude alto, devido à intensidade das atividades antrópicas sobre 0 meio e à pressão sobre os recursos naturais, aumentando a geração de resíduos e os problemas no descarte.

No primeiro momento, a solução para o lixo era considerada simples, pois bastava descartá-lo nas áreas mais distantes dos centros urbanos, fora do alcance da população. O avanço da tecnologia e da ciência proporcionou uma diferente compreensão sobre a gestão de resíduos sólidos, focado na busca da melhor qualidade ambiental e da saúde para o homem. Entretanto, ainda existem locais onde os resíduos são depositados de forma inapropriada no Brasil, e muitas vezes nem são afastados do alcance visual da população (PEDROSA; NISHIWAKI, 2014).

Os resíduos sólidos urbanos (RSU) são de origem domiciliar e pública. Esse último é composto pelos resíduos advindos da varrição, da limpeza de logradouros e de vias públicas, além de outros serviços de limpeza urbana. Ao longo do tempo, os parâmetros quantitativos e qualitativos dos resíduos sofreram alterações; no entanto, o modo de gerilos não tem acompanhado tais mudanças (SANTIAGO; DIAS, 2012).

Quando dispostos de forma inadequada no ambiente, os resíduos sólidos podem acarretar poluição do ar, degradação do solo, intensificação de enchentes e contaminação de águas superficiais e subterrâneas pelo chorume produzido. Também pode provocar o aumento da incidência de doenças causadas por vetores que se proliferam com o acúmulo do lixo, catação em condições insalubres na rua e em áreas de disposição, levando até a prejuízos turísticos (COUTINHO et al., 2011; JACOBI; BESEN, 2011).

$\mathrm{Na}$ intenção de promover os princípios e as diretrizes para o gerenciamento dos resíduos sólidos, em 02 de agosto de 2010 foi instituída no Brasil a Política Nacional dos Resíduos Sólidos (PNRS) pela Lei 12.305. Após 20 anos tramitando no Congresso Nacional, essa lei estabeleceu um novo marco regulatório para o país. Um dos objetivos da lei, especificado no Art. $7^{\circ}$, é que, prioritariamente, deve ser obedecida a ordem de 
"não geração, redução, reutilização, reciclagem e tratamento dos resíduos sólidos, bem como disposição final ambientalmente adequada dos rejeitos" (BRASIL, 2010).

Apesar dessas premissas estabelecidas na legislação, a geração de RSU no país apresentou, em 2014, um aumento de 2,9\% em relação ao ano anterior, sendo superior ao índice de crescimento populacional no mesmo período, que teve o valor relativo de 0,9\%. Em termos de quantidade, naquele ano, a geração foi de 78, 6 milhões de toneladas. Desta quantidade gerada, 51,8\% foram destinados em aterros sanitários, e 0 restante, 29.659.170 ton.ano-1, depositados em lixões e aterros controlados, o qual, em termos de sustentabilidade ambiental, não se diferencia do lixão, sendo ambas as formas inadequadas de disposição final dos RSU (ABRELPE, 2014).

$\mathrm{Na}$ intenção de mudar esta realidade, buscam-se modelos direcionados para estarem em consonância com as premissas operacionais da gestão integrada dos resíduos sólidos, as quais devem considerar o controle social e os princípios do desenvolvimento sustentável (BRASIL, 2010). Assim, alcançar a articulação destes elementos mostra-se relevante para a estruturação da gestão integrada de resíduos sólidos.

\subsection{Relação entre a gestão de RSU e a visão sistêmica}

A visão sistêmica é a adoção do pensamento holístico, o qual segundo Capra (1996, p. 24) "concebe o mundo como um todo integrado, e não como uma coleção de partes dissociadas". É o contraponto ao pensamento mecanicista, tal como o de René Descartes e o método do pensamento analítico que consiste em avaliar um fenômeno a partir das propriedades de suas partes. Apesar de ser possível identificar individualidades em qualquer sistema, não há isolamento entre elas e a representação do todo nunca será a simples soma das partes.

Segundo Batista (2013), a primeira referência sobre a existência de interrelacionamento e interdependência entre os seres vivos partiu do Sir John Arthur Thomson (1861-1933), naturalista escocês. Esse autor utilizou a metáfora da teia da vida para representar a ideia de inter-relacionamento e ramificação. Seguindo a lógica, nenhuma parte da trama de fios consegue ficar fora do todo. Assim, a natureza é vista como um sistema de conexões em que o isolamento é impossível.

Os biólogos foram os primeiros a falar em pensamento sistêmico ao considerar os organismos ou sistemas vivos como totalidades integradas cujas propriedades surgem 
das interações e das relações entre as partes (Capra, 1996). A teoria geral dos sistemas foi desenvolvida pelo biólogo L. Von Bertalanffy, em 1940, com o estudo de sistemas vivos considerados abertos, devido à troca de matéria e energia com o meio. Nesse ponto, os problemas que cercam os seres humanos devem ser tratados como sistemas, considerando os contornos, componentes e inter-relações, bem com a ideia de subsistemas contidos nos sistemas, e por serem abertos, interagem entre si e com o ambiente (MISOCZKY, 2003).

A adoção da perspectiva sistêmica contribui para a ideia de que a humanidade e a natureza estão integradas, e, portanto, não podem ser analisadas como elementos distintos e independentes. Desta forma, todo fenômeno natural afeta os seres humanos, bem como toda ação antrópica afeta o meio ambiente, mesmo que indiretamente ou superficialmente. Este fato demonstra que esta relação exige cuidados, visto que agressões sobre um ou outro acabam por afetar eles próprios (SILVA, 2014). É o caso da disposição irregular dos resíduos sólidos urbanos, ação que pode causar a contaminação da água, do solo e do ar, afetando a saúde pública.

A abordagem sistêmica é, desta forma, uma maneira de compreender o mundo, um modelo de gestão. Em relação aos resíduos sólidos, Lopes (2003, p. 30) afirma que "Gestão de Resíduos Sólidos são todas as normas e leis relacionadas a estes" e "Gerenciamento Integrado de Resíduos Sólidos todas as operações que envolvam os resíduos, como coleta, transporte, disposição final, entre outras".

Na PNRS, se define gestão integrada como o conjunto de ações voltadas para a busca de soluções para os resíduos sólidos, considerando as dimensões política, econômica, ambiental, cultural e social, sob a premissa do desenvolvimento sustentável. Já o gerenciamento de resíduos sólidos, como o conjunto de ações exercidas, direta ou indiretamente, nas etapas de coleta, transporte, transbordo, tratamento e destinação final ambientalmente adequada dos resíduos e rejeitos. A visão sistêmica está presente, de forma explícita, na referida legislação como um princípio a ser seguido na gestão dos resíduos sólidos, que considera as variáveis ambiental, social, cultural, econômica, tecnológica e de saúde pública (BRASIL, 2010). Por outro lado, para Rodrigues e Rippel (2015) o dinamismo desse conceito traz a importância de compreender o desenvolvimento via a construção de mecanismos de mensuração, sendo necessário o estabelecimento de indicadores de sustentabilidade.

Os indicadores de sustentabilidade são ferramentas que auxiliam no monitoramento da operacionalização do desenvolvimento sustentável, tendo como função 
principal fornecer informações sobre o estado das diversas dimensões que o compõe (CARVALHO et al., 2011). São exemplos de indicadores de sustentabilidade a Pegada Ecológica, o Painel da Sustentabilidade, o Índice de Sustentabilidade Ambiental (ISA), o Índice de Desenvolvimento Humano (IDH), a Pegada de Carbono, dentre outros parâmetros (VAN BELLEN, 2002; PÉREZ, 2012).

Mas não somente de forma direta está incluída a visão sistêmica na PNRS. O conceito do pensamento holístico, ou seja, a inter-relação entre as partes de um sistema, e deste com o meio, está presente nas diretrizes propostas por esta legislação para a gestão e o gerenciamento integrado dos resíduos sólidos. Nela é incentivada a integração entre os diferentes setores envolvidos na geração de resíduos, e observado o planejamento dos serviços públicos que tenham envolvimento com a gestão de resíduos sólidos, para que ocorram de forma associada (BRASIL, 2010).

Segundo Gunther e Grimberg (2006), a gestão integrada é um conceito interdisciplinar e em construção, que pode ser entendido por três níveis relacionados. O primeiro refere-se às etapas de operação; o segundo, à intersetorialidade entre as diferentes esferas de governo; e o terceiro, à articulação entre os múltiplos agentes sociais: o governo, o setor privado e a sociedade.

Segundo Besen et al. (2014), a gestão integrada e sustentável de resíduos resulta numa hierarquia de objetivos que incluem a minimização da geração de resíduos; a redução dos impactos negativos dos resíduos; a maximização da reutilização, da reciclagem e da compostagem; a recuperação de energia; a promoção de tratamento e a disposição final de forma ambientalmente segura. Toda esta hierarquia é promovida no texto da PNRS e implica em mudanças de hábitos de consumo da sociedade, separação na origem dos resíduos recicláveis, serviços adequados de coleta pública e privada para logística reversa dos resíduos, inclusão social de catadores e o retorno para cadeia produtiva dos materiais.

A solução para reverter tal problema pode estar no desenvolvimento de modelos integrados e sustentáveis, baseado numa visão sistêmica, segundo orientação da Política Nacional de Resíduos Sólidos. No que tange a relação entre saúde pública e disposição de resíduos, Graudenz et al (2012) ressaltam que pesquisas interdisciplinares podem melhorar os conhecimentos dos riscos à saúde humana decorrentes de morar na proximidade de aterros sanitários, bem como daqueles que trabalham nos aterros, demonstrando que a visão sistêmica poderá complementar a compreensão da realidade. 
Procurando acompanhar o paradigma holístico, a gestão dos resíduos sólidos urbanos tem evoluído em busca de uma visão sistêmica, promovendo a ideia de um sistema aberto no qual todos os atores - sociedade, governo, empresas privadas, organizações não governamentais - interagem em todas as etapas de gerenciamento e são corresponsáveis pelo sucesso delas. Essa interação tem um caráter dinâmico e variável no tempo e em diversas escalas, que vão da individual à global. Nessa perspectiva é percebida a inter-relação do sistema de RSU com os demais sistemas urbanos, como o de esgoto, pluvial e paisagístico (GODECKE et al., 2012).

Nesse sentido, se considera os impactos causados em corpos hídricos da disposição inadequada dos RSU. Considera-se destinação inadequada o descarte direto em corpos de água, na rua e em terrenos vazios ou em lixões, onde não há controle quanto ao tipo e local de disposição dos resíduos, nem tratamento dos líquidos e gases provenientes da decomposição dos materiais orgânicos.

O descarte direto de resíduos em canais ou rios provoca a contaminação da água e o assoreamento; e a disposição na rua e em calçadas, no entupimento de bueiros, com consequente aumento das enchentes em épocas de chuva (JACOBI; BESEN, 2011). O risco ocorre quando a água contaminada é usada para abastecimento ou para irrigação, demonstrando que o problema não é pontual, ao contrário, levando a sentir os efeitos do problema para locais distantes da origem (FERREIRA; ROSELEN, 2012). Evidencia-se, desse modo, a inter-relação entre os elementos de um sistema urbano, de maneira que um não pode ser gerido isoladamente ao outro. Tal fato demonstra a necessidade da abordagem sistêmica quando se trata da gestão e do gerenciamento dos resíduos.

\section{CONCLUSÕES}

A adoção do conceito de sustentabilidade nos processos e sistemas, bem como em organizações, tem sido apontada como solução para os problemas ambientais. No entanto, este conceito é apresentado de maneira ampla e vaga, mesmo existindo extensa bibliografia sobre o tema. Assim, o termo é usado vinculado a diferentes setores das atividades antrópicas. Entretanto, muitas vezes sem a objetividade necessária para a efetiva solução de problemas, não representando de fato compromisso vinculado à melhoria dos indicadores socioambientais, pois foca na essência o alcance de um resultado econômico satisfatório. Portanto, são necessárias e relevantes as mudanças de 
hábitos e paradigmas para uma efetiva alteração de discurso e visão de mundo dos individuos.

A gestão e o gerenciamento dos resíduos sólidos urbanos são uma das principais questões e das mais custosas financeiramente a serem resolvidas pela Administração Pública. A chave do problema está em reduzir a geração excessiva de resíduos e destinálos de forma ambientalmente segura. Tal como prediz a Política Nacional de Resíduos Sólidos, a gestão deve ter como princípio a visão sistêmica. A inserção desta abordagem significa integrar os diferentes setores, segmentos e instrumentos às dimensões econômica, social, ambiental e cultural na tomada de decisão dos gestores públicos, bem como nortear a mudança de postura da sociedade civil.

A falta desta abordagem sistêmica pode resultar em dificuldades para implantação e manutenção do gerenciamento de resíduos sólidos, não contemplando todos os sistemas e os aspectos relacionados a estes. É urgente propiciar meios para a mudança de valores e hábitos, pois é evidente que padrões de produção e consumo mais sustentáveis, bem como o gerenciamento adequado dos resíduos, podem significar a elevação da qualidade socioambiental.

\section{REFERÊNCIAS}

ARAUJO, G. C.; BUENO, M. P.; SOUSA, A. A.; MENDONÇA, P. S. M. Sustentabilidade empresarial: conceitos e indicadores. In: CONGRESSO VIRTUAL BRASILEIRO DE ADMINISTRAÇÃO, 3., 2006. Anais... Brasil, 2006.

ASSOCIAÇÃO BRASILEIRA DE EMPRESAS PÚBLICAS DE LIMPEZA E RESÍDUOS ESPECIAIS - ABRELPE. Panorama dos resíduos sólidos do Brasil. 2014. Disponível em: < http://www.abrelpe.org.br/Panorama/panorama2014.pdf >. Acesso em: 29 maio 2016.

BATISTA, C. R. R. O caminho da ecologia humana para um mundo em crescimento. Revista Vitas, v. 3, n.7, p. 1-13, 2013.

BESEN, G. R.; RIBEIRO, H.; GUNTHER, W. M. R.; JACOBI, P. R. Coleta seletiva na Região Metropolitana de São Paulo: impactos da Política Nacional de Resíduos Sólidos. Abiemt. Soc., v. 17, n.3, p. $253-272,2014$.

BRASIL. Lei 12.305 que institui a Política Nacional de Resíduos Sólidos; altera a lei no 9.605, de 12 de fevereiro de 1998; e da outras providências. Diário Oficial da União, 03 ago. 2010.

BRITO, F. E. M. Rachel Carson e os gritos da Primavera silenciosa. O olho da história, n.15. 2010. Disponível em: < http://oolhodahistoria.org/n15/artigos/francisco.pdf >. Acesso em: 22 maio 2016.

BURRELL, G.; MORGAN, G. Sociological paradigms and organizational analysis: elements of the sociology of corporate life. London: Heinemann, 1979. 
CAPRA, F. A teia da vida: uma nova compreensão científica dos sistemas vivos. São Paulo: Cultrix, 1996.

CARVALHO, J. R. M.; CURI, W. F.; CARVALHO, E. K. M. A. CURI, R. C. Proposta e validação de indicadores hidroambientais para bacias hidrográficas: estudo de caso na sub-bacia do alto curso do Rio Paraíba, PB. Sociedade e Natureza, Uberlândia, v. 23, n. 2, p. 295-310, 2011.

COUTINHO, R. M. C.; COUTINHO, A. L. O.; CARREGARI, L. C. Incineração: uma solução segura para o gerenciamento de resíduos sólidos. In: CLEANER PRODUCTION INITIATIVES AND CHALLENGES FOR A SUSTAINABLE WORLD, 3., 2011. Anais...São Paulo, 2011.

ECHEGARAY, F.; AFONSO, M. H. F. Resposta às mudanças climáticas: inovação tecnológica ou mudança de comportamento individual? Estudos Avançados, v.28, n. 82, p. 155-174, 2014.

FERNANDES, P. A. A.; CÂNDIDO, G. A. Da sustentabilidade à competitividade: um caminho viável? Rev. Ges. Sust. Ambient., v.4, n.1, p. 55 - 76, 2015.

FERREIRA, F.; BOMFIM, Z. A. C. Sustentabilidade ambiental: visão antropocêntrica ou biocêntrica? Ambientalmente sustentable, v. 1, n. 9-10, p. 37-51, 2010.

FERREIRA, D. A.; ROSOLEN, V. Disposição de resíduos sólidos e qualidade dos recursos hídricos no município de Uberlância/MG. Horizonte Científico, v.6, n. 1, p. 1-21, 2012.

GODECKE, M. V.; CHAVES, I. R.; NAIME, R. H. Gestão de resíduos sólidos urbanos no Brasil: o caso de Canoas, RS. Rev. Elet. em Gestão, Educação e Tecnologia Ambiental, v. 7 n.7, p. $1430-1439,2012$.

GRAUDENZ, G. S.; AGUIAR, A. de O; RIBEIRO, A. P. Disposição final de resíduos em aterros sanitários e saúde humana. Rev. Ges. Sust. Ambient., v. 1, n.1, p. 47 -69, 2012.

GÜNTHER, W. M. R.; GRIMBERG, E. Directrices para La gestión integrada y sostenible de residuos sólidos urbanos enAmerica Latina y el Caribe. 1. ed. São Paulo: Asociación Interamericana de Ingeniería Sanitária y Ambiental-AIDIS, 2006.

GURSKI, B.; GONZAGA, R.; TENDOLINI, P. (2012). Conferência de Estocolmo: um marco na questão ambiental. Administração de Empresas em Revista, v. 11, n.12, p. 65 - 79, 2012.

GRÜN, M. Ética e educação ambiental: a conexão necessária. 1. ed. São Paulo: Papirus, 1996.

JACOBI, P. R.; BESEN, G. R. Gestão de resíduos sólidos em São Paulo: desafios da sustentabilidade. Estudos Avançados, v. 25, n.71, p.135-158, 2011.

LEANDRO, L. A.; GOMES, C. M.; CASTRO, K. N. V. DE; CÂSTRO, E. M. N. V. O futuro da gestão socioambiental: uma análise critica sobre a crise ambiental brasileira. Rev. Ges. Sust. Ambient., v. 4, n. 2, p.144 - 162, 2015.

LIRA, S. H.; FRAXE, T. J. P. O percurso da sustentabilidade do desenvolvimento: aspectos históricos, políticos e sociais. Revista Monografias Ambientais - REMOA, v. 14, n. 12, p. 3172 3182, 2014.

LOPES, A. A. Estudo da gestão e do gerenciamento integrado dos resíduos sólidos urbanos no município de São Carlos (SP). Dissertação (Mestrado) - Universidade de São Paulo, São Carlos, 2003. 
MISOCZKY, M. C. A. Da abordagem de sistemas abertos à complexidade: algumas reflexões sobre seus limites para compreender processos de interação social. Cadernos EBAPE.br, v. 1, n.1, p. 1- 17, 2003.

MUCELIN, C. A.; BELLINI, M. Lixo e impactos ambientais perceptíveis no ecossistema urbano. Soc. nat. [online], v. 20, n. 1, p. 111-124, 2008.

ODUM, E. P. Ecologia. Rio de Janeiro: Guanabara Koogan, 1998.

OLIVEIRA, L. R. O.; MARTINS, E. F.; LIMA, G. B. A. Evolução do conceito de sustentabilidade: um ensaio bibliométrico. Relatórios de Pesquisa em Engenharia de Produção, v.10, n. 4, p. 117, 2010.

OLIVEIRA, N. Desenvolvimento Sustentável e noção de sustentabilidade. In: MARTINS, C.L.B., \& OLIVEIRA, N. (Org.). Indicadores econômicos-ambientais na perspectiva da sustentabilidade. Porto Alegre: FEE; FEPAM, 2005.

ORGANIZAÇÃO DAS NAÇÕES UNIDAS. Relatório Brundlant. 1987. Disponível em: < http://www.un.org/documents/ga/res/42/ares42-187.htm >. Acesso em: 21 mai. 2016.

PEDROSA, D. S. F.; NISHIWAKI, A. A. M. Resíduos Sólidos: Uma visão prospectiva a partir da análise histórica da gestão. In: El-Deir, S. G. (org.) Resíduos Sólidos: perspectivas e desafios para a gestão integrada. Recife: EDUFRPE, 2014. p. 393.

PEREIRA, C. M. S. S. Gestão sistêmica de resíduos sólidos para a UEFS: subsídios para a construção de uma política participativa. Dissertação (Mestrado) - Universidade Estadual de Feira de Santana, Feira de Santana, BA, 2010.

PEREIRA, S. S. Reflexões sobre o processo de urbanização e a necessidade de gestão ambiental: o caso dos resíduos de serviço de saúde da cidade de Campina Grande/PB. Reunir Rev. de Administração, Contabilidade e Sustentabilidade, v. 2, n. 1, p. 87 - 103, 2012.

PÉREZ, R. M. I. Indicadores de sustentabilidad: utilidade y limitaciones. Teoría e Praxis, p. 102126, 2012.

RÊGO, N. J. F. Resenha: Conhecimento e consciência do desenvolvimento urbano. Rev. GEOMAE, v. 3, n. 1, p. $113-118,2012$.

RHODE, G. M. Mudanças de paradigma e desenvolvimento sustentado. In: CAVALCANTI, C. (Org.). Desenvolvimento e natureza: estudos para uma sociedade sustentável. São Paulo: Cortez, 1995.

RODRIGUES, F. R.; RIPPEL, R. Desenvolvimento sustentável e técnicas de mensuração. Rev. Ges. Sust. Ambient., v. 4, n. 3, p. $73-88,2015$.

ROSA, A. S.; DALMOLIN, R.S. D.; COPETTI, A. C. C. A poluição causada por aterros de resíduos sólidos urbanos sobre os recursos hídricos. Ciência e natura, v. 34, n.1, p. 107-118, 2012.

SANTIAGO, L. S.; DIAS, S. M. F. Matriz de indicadores de sustentabilidade para a gestão de resíduos sólidos urbanos. Rev. Eng. Sanit.Ambient., v. 17, n. 2, p. 203 - 212, 2012.

SARTORI, S.; LATRONICO, F.; CAMPOS, L. M. S. Sustentabilidade e desenvolvimento sustentável: uma taxonomia no campo da literatura. Ambiente e sociedade, v. 17, n. 1, p. 1-22, 2014. 
SILVA, E. L.; MENEZES, E. M. Metodologia da pesquisa e elaboração da dissertação. 4. ed. Florianópolis: UFSC, 2005.

SILVA, S. S. Proposta de um modelo de análise do comprometimento com a sustentabilidade. Ambiente e Sociedade, v. 17, n. 3, p. 35-54, 2014.

VAN BELLEN, H. M. Indicadores de Sustentabilidade: Uma análise comparativa. 2002. 235 p. Tese (Doutorado em Engenharia de Produção) - Curso de Pós-Graduação em Engenharia de Produção, Universidade Federal de Santa Catarina, Santa Catarina, 2002. 